\title{
Invenção e estabilização: uma experiência com crianças autistas em dispositivos de Saúde Mental*1
}

\section{Invention and stabilization: an experience with autistic children in Mental Health units}

Beatriz Alves Viana*2

Luis Achilles Rodrigues Furtado*3

Camilla Araújo Lopes Vieira*4

$O$ artigo aborda o valor do trabalho de invenção como forma de estabilização na clínica do autismo, a partir de um projeto de extensão universitária voltada a crianças em grave sofrimento psíquico, que tem a psicanálise como direção de trabalho e de tratamento. Durante esta vivência, podemos presenciar - a partir do acompanhamento do movimento dessas crianças - sujeitos que, por meio de suas manifestações particulares, buscavam produzir algo que estabilizasse sua desorganização psíquica. Assim, entende-se que o trabalho subjetivo implicado no ato da invenção enquanto o ato que um sujeito realiza uma construção singular de elementos de sua história a partir de materiais já existentes - pode redundar numa estabilização e mediação com o campo do Outro por parte do sujeito, algo que foi possivel observar nessa experiência clínica.

Palavras-chave: Autismo, psicanálise, invenção, estabilização

${ }^{* 1}$ Este artigo é fruto de uma pesquisa de produtividade financiada pela Fundação Cearence de Apoio ao Desenvolvimento Científico e Tecnológico - FUNCAP, intitulada "O vazio, o silêncio e o Outro na clínica do autismo: uma articulação entre topologia, música e psicanálise'.

*2 Universidade Federal do Rio de Janeiro - UFRJ (Rio de Janeiro, RJ. Brasil).

${ }^{*} 3,4$ Universidade Federal do Ceará (Sobral, CE, Brasil). 


\section{Introdução}

Este artigo aborda o valor do trabalho de invenção como forma de estabilização na clínica do autismo, a partir de uma experiência de extensão universitária voltada a crianças em grave sofrimento psíquico, que tem a psicanálise como direção de trabalho e de tratamento. Este projeto de extensão é formulado a partir de três pressupostos fundamentais: o Político, o Ético e o Clínico, relacionados, respectivamente, à intervenção da psicanálise nos dispositivos públicos de atenção à Saúde Mental; à operacionalização do discurso analítico nesse espaço a partir da ética psicanalítica; e o tratamento desses sujeitos é orientado a partir da suposição do inconsciente e da consideração da transferência.

Durante esta vivência, pudemos presenciar — a partir do acompanhamento do movimento daquelas crianças - sujeitos que, por meio de suas manifestações particulares, buscavam produzir algo que estabilizasse sua desorganização psíquica. Sabemos que as manifestações peculiares apresentadas nos quadros de psicose e de autismo, ligam-se ao modo como esses sujeitos são afetados pelo campo do Outro, muitas vezes constatando-se uma abolição do ordenador da cadeia significante, uma foraclusão do Nomedo-Pai (Lacan, 1955-56/1988). É justamente em relação a essa falta de mediação (Lacan, 1964/1993; 1969/2003b) na relação com o Outro que esses indivíduos se engajam no trabalho de constituir-se como sujeito (Lacan, 1958/1998c).

Assim, parte-se da hipótese de que o trabalho implicado no ato da invenção pode produzir uma mediação na relação do sujeito com o Outro, fazendo uma suplência ao que fora abolido ou inscrevendo a mediação simbólica conforme o caso. Neste estudo considera-se a noção de invenção enquanto o ato que um 


\section{SAÚDE MENTAL}

sujeito realiza uma construção singular de elementos de sua história a partir de materiais já existentes em que este se engaja (Miller, 2003).

Foi possível observar nesse trabalho clínico, que o reconhecimento das produções desses sujeitos como uma invenção, através das ferramentas e materiais de seu interesse, possibilitou a construção de um laço social e uma estabilização, assim como Joyce, que - ocupando-se da materialidade significante e dos restos sonoros impostos em sua história - produziu uma amarração ao laço social (Lacan, 1975-76/2007). Dessa forma serão expostas algumas vinhetas clínicas a partir das quais foi possível depreender um efeito de estabilização por meio da invenção de algo singular pela criança. Ademais, é importante destacar que o presente artigo realiza a discussão da experiência e se fundamenta nos três pressupostos citados anteriormente.

\section{Aposta no sujeito: a clínica do autismo em questão}

Apesar da recusa do sujeito autista ao endereçamento, à comunicação, ao discurso e à produção de sentido, os achados clínicos e depoimentos autobiográficos de ditos autistas confirmam que os mesmos não estão exilados do "cancro inato da linguagem" (Lacan, 1975/1991). Testemunhamos isso com aqueles que têm acesso à fala, com as composições musicais de Donna Williams, com as criações singulares de Temple Grandin (2006) ou na originalidade do uso da linguagem por Joey, garoto atendido por Bruno Bettelheim (1967/1987) na década de 1940. Isso demonstra e comprova a expressão "mestre da linguagem", utilizada por Lacan (1953-54/1979, p. 102) referindo-se a Dick, garoto autista atendido por Melanie Klein (1930/1996). Para Lacan (1953-54/1979), Dick "é um sujeito que está aí e que, literalmente, não responde" (p. 102), ou seja, apesar de sua recusa a uma enunciação no nível da palavra e da fala [parole], estava imerso na linguagem e no campo verbal.

Presencia-se constantemente nessa clínica, o trabalho singular e constante do sujeito de lidar com a linguagem (Lacan, 1967/2003a). Assim, destaca-se a importância do ato analítico de tomar os comportamentos desses sujeitos como manifestação significante, não no sentido de uma ação interpretativa totalmente indiscriminada, mas de situá-los em uma posição de produção de fala, intervindo através do ato e da palavra.

Ainda nesse sentido, Lacan discute em "Função e campo da fala e da linguagem" (1953/1998b), acerca da estrutura do inconsciente articulado à 
linguagem, propondo recuperar a importância da noção de fala enquanto o principal recurso e possibilidade da experiência analítica. Tal noção torna-se, portanto, essencial para investigar de que forma a experiência analítica opera em relação a pacientes que parecem recusar a manifestar-se através da fala, como nos casos diagnosticados com autismo.

Considera-se que a clínica da psicose também segue uma orientação proveniente da análise do que a produção da fala articula. Nesse sentido, destacam-se dois textos freudianos em que o autor discute sobre as particularidades da fala na paranoia e na esquizofrenia: "Notas psicanalíticas sobre um relato autobiográfico de um caso de paranoia" (1911) e "O inconsciente" (1915) que abordam, respectivamente, a articulação delirante de Schereber como efeito de um reinvestimento na realidade e uma tentativa de estabilização; e o investimento nas representações de palavras como uma tentativa de recuperação do objeto através de elementos verbais que resultam na construção delirante. Destacamos aqui a tomada das palavras como coisas, ou seja, aquilo que elas possuem de sua vertente real, na sua materialidade, equívocos sonoros dependentes diretos da enunciação e da musicalidade de lalíngua. ${ }^{1}$

316 Em "Formulações sobre a causalidade psíquica" (1946/1998a), Lacan retoma rigorosamente os textos de Freud para destacar os fenômenos da psicose relacionados ao campo da linguagem e o seu tratamento a partir da fala. Dessa forma, a psicose é discutida a partir de uma causalidade significante e do trabalho inconsciente, sendo "vívida no registro do sentido" (Lacan, 1946/1998a, p. 166). Lacan (1953/1998b, p. 281) aponta que a psicose comporta um modo de fala radical, sem dialetização, e propõe, como direção de tratamento, que o analista tome as produções desses sujeitos em sua literalidade e materialidade, a partir de uma posição de "secretário do alienado" (Lacan, 1955-56/1988, p. 235).

No que se refere ao autismo, Lacan traz indicações precisas sobre o tema. Afirma que a recusa manifesta pelos sujeitos que "tapam os ouvidos" prova que já estão na linguagem, uma vez que a atitude da criança comprova que não estão num suposto estágio pré-verbal, "já que é do verbo que se protegem" (Lacan, 1967/2003a, p. 365). Em Genebra, Lacan (1975/1991) declara que os

${ }^{1}$ Lalíngua é um conceito elaborado por Lacan (1972-73/1985) para falar das marcas da materialidade da linguagem sobre o sujeito, que remete à lalação das crianças anterior à articulação de significantes. 


\section{SAÚDE MENTAL}

autistas "articulam muitas coisas" e resta-nos descobrir onde o escutaram, o que poderia ser o indicativo da presença do campo do Outro ou da existência de uma alteridade. Entendemos que o uso do verbo "articular" é uma referência à dimensão da linguagem em ato, não necessariamente falada.

Existem ainda outras indicações. A primeira remete ao fato de os autistas aparentemente não escutarem quando alguém se ocupa deles; e a segunda trata-se de que, como fez Klein com Dick (Lacan, 1953-54/1979), temos muito a dizer a esses indivíduos, que primeiro se constituem como sujeitos que escutam muitas coisas (Lacan, 1975/1991, p. 134). Trata-se de uma posição importante, pois indica a direção do tratamento como algo que o analista deve falar e não "interpretar". Inscrever, chapar, como Klein, um primeiro afresco (Lacan, 1953-54/1979, p. 105).

Nosso ponto de vista sobre o autismo, nesse contexto, acompanha tais indicações de Lacan.

Diferentemente de Maleval (2018) e Laurent (2013) - que são influenciados diretamente pelas teorizações de Lefort e Lefort (2003; 1998; 1980) — , insistimos nas discordâncias explícitas de Freud (1921/1992a; 1921/1992b), de Lacan (1975/2016) e de Winnicott (1967/1972) quanto à aceitação do termo "autismo" na psicanálise (Furtado, 2012). Drapier (2012, p. 38), discorda de Maleval (2009), afirmando que Lacan não falou de "autismo", mas de "autistas".

Essa aceitação da generalidade do termo tem, por consequência, sua absorção como conceito psicanalítico e como uma estrutura. Longe de tomarmos, privilegiadamente, a sintomatologia para justificar a categoria, estando, assim, em consonância com a psiquiatria contemporânea, tratamos a dimensão significante proveniente dos objetos de interesse dos sujeitos, suas invenções, produções e relatos. Damos um tratamento análogo ao que Lacan dava às alucinações, pois são elas que localizam a posição do sujeito (Soler, 2007). O que conseguimos depreender daí são sujeitos petrificados sob efeitos da holófrase (Peusner, 2016), algo da "dimensão do psicótico" (Lacan, 1964/1993, p. 225), mas não necessariamente uma psicose, pois encontram-se numa relação com o Outro na qual não há mediação e levantam a hipoteca de seu ser.

Quando falamos dos "autistas", referimo-nos aos "ditos-autistas", submetidos à holófrase, que recebem esse diagnóstico ou mantêm sintomas que se encaixam nesse significante psiquiátrico e que podem ser ou não psicóticos, podendo se desdobrar em mecanismos de defesa estruturais diferentes (Lacan, 1969/2003b). Drapier (2012) refere-se à "síndrome 
autística" como uma patologia sobreposta e que nada nos diz sobre a estrutura em jogo. Assim, do ponto de vista psiquiátrico e sintomatológico podemos falar de autistas, mas não necessariamente do ponto de vista estrutural psicanalítico.

Destacamos que há uma particularidade na prática psicanalítica com crianças, pois na maioria das vezes não é a criança que demanda um tratamento, mas seus pais, cuidadores etc. Quanto a isso, Lacan (1969/2003b) propõe que aquilo que sustenta a história singular infantil é a forma como se apresentou o desejo para os pais, o que nos orienta a explorar não apenas a história familiar, mas o modo como foram articulados para criança: o saber, o objeto, a falta, o gozo e o campo do Outro.

É sob o suporte desses aspectos teóricos e clínicos, que a experiência de extensão mencionada se apoia para sua construção e manejo. Assim, cabe discorrer mais detalhadamente sobre o funcionamento desse projeto, antes de realizarmos articulações teóricas propriamente ditas.

\section{Sobre a experiência de extensão: projeto "Água de Chocalho"}

\section{Criação e construção do projeto}

O projeto "Água de Chocalho" é destinado a crianças em grave sofrimento psíquico - que optamos por nomear com Pablo Peusner (2016, p. 132) de "crianças sujeitas à holófrase ${ }^{2}$ — ocorre em um CAPS II (Centro de Atenção Psicossocial) e no Serviço de Psicologia Aplicada de uma Universidade Federal. O título do projeto intitulado "Água de Chocalho" faz referência à prática — folclórica — nordestina, descrita por Costa (1908/2004), que visa evitar problemas de linguagem na criança e curar o atraso na fala. De acordo com essa prática popular, as crianças que tardam a falar devem beber água dentro de um chocalho para que tenham acesso à fala. Destarte, a nomeação dada ao projeto parte do próprio objetivo geral do trabalho: possibilitar às crianças sob o efeito da holófrase manifestações de

${ }^{2}$ Segundo Lacan (1958-59/2002), a holófrase é o processo no qual a dupla de significantes primordiais, $\mathrm{S}_{1}$ (significante mestre) e $\mathrm{S}_{2}$ (significante do saber do Outro) encontra-se sem articulação e sem intervalos suspensivos, constituindo um sujeito que se cristaliza em um aspecto monolítico, rejeitando uma mediação simbólica. 


\section{SAÚDE MENTAL}

fala, a partir dos recursos sonoros ou outras ferramentas que sirvam como um canal através do qual a palavra possa circular.

Esse projeto está vinculado ao Laboratório de Clínica Sujeito e Políticas Públicas - CLIPSUS, na referida Universidade Federal e atualmente atende cerca de vinte famílias de crianças que recebem o diagnóstico ou que têm queixas relacionadas ao autismo.

Tendo em vista que um dos maiores desafios no âmbito da Saúde Pública/Saúde Mental se refere à construção de uma política voltada para esses sujeitos e que leve em consideração suas singularidades (Brasil, 2005), essa ação pretende propor novas alternativas em relação às formas de lidar com esse público, buscando repensar maneiras de auxiliá-los em suas dificuldades e conduzir novas práticas de cuidados para essas pessoas. No contexto da cidade onde o projeto se localiza, tem-se a ausência de um CAPS Infanto-Juvenil, e a presença de um único serviço geral (CAPS II) que comporta quase toda a demanda de casos direcionados ao campo da Saúde Mental. Logo, é também a partir dessa demanda que surge a possibilidade de um dispositivo que contribua com a inclusão desses sujeitos, considerando suas peculiaridades, seus impasses e suas construções próprias para lidar com o seu sofrimento. Ademais, tal projeto nasce também das exigências impostas pelos casos que já eram acompanhados em articulação com a rede de Saúde Mental do município por parte dessa Universidade pública e gratuita.

As atividades propostas pelo projeto de extensão englobam: atendimento das crianças e seus responsáveis, construção de casos clínicos, supervisão clínica e institucional, reuniões com a equipe da rede intersetorial e dos serviços envolvidos no acompanhamento da criança, oficinas de música e reuniões com a equipe responsável. Destacamos a importância das reuniões em equipe e a supervisão clínica, uma vez que esses espaços estão para além de uma circulação de informações sobre o caso, mas trata-se de um lugar onde os diversos discursos acerca da criança podem ser sustentados e, portanto, possibilitar um reposicionamento do saber em cada membro da equipe.

$\mathrm{Na}$ época em que as atividades no projeto foram iniciadas, tinha-se a discussão em torno da possibilidade de um espaço que se dirigisse não exclusivamente às crianças autistas, visando possibilitar um suporte de inclusão. Outro ponto discutido dizia respeito aos impasses implicados na prática analítica dentro da instituição, uma vez que no trabalho interdisciplinar com rede de Saúde Mental, seguíamos concretamente as diretrizes estabelecidas pelas políticas públicas desse campo, sem, no entanto, haver o afastamento dos princípios éticos, clínicos e teóricos da psicanálise no que concerne à sua práxis. 
Como dissemos anteriormente a fim de sustentarmos as condições básicas para o trabalho, foram traçados os três pressupostos já mencionados anteriormente que nortearam a prática, sem, contudo, torná-los proposições rigorosas e puramente ideológicas, sempre considerando o manejo da singularidade de cada caso. Dessa forma, discutiremos sobre cada um desses pressupostos apontando seus aspectos mais relevantes.

\section{Pressuposto político: a psicanálise, o autismo e a instituição}

A necessidade de articulação intersetorial para o tratamento de crianças autistas, bem como a construção de um Projeto Terapêutico Singular (PTS) com todos os envolvidos no caso, põe em questão o aspecto clínico da prática em Saúde Mental e o alcance político das ações realizadas, impondo, muitas vezes, impasses relacionados à articulação da dimensão clínica com o ideal político referente ao campo psicossocial. No entanto, apostamos que tais posições não são incompatíveis e podem ser articuladas.

Várias diretrizes que instituem o cuidado na Atenção Pública, direcionado às crianças em grave sofrimento psíquico, vêm sendo formuladas e efetivadas,

320 como, por exemplo, o documento Caminhos para uma Política de Saúde mental Infanto-Juvenil (Brasil, 2005) lançado pelo Ministério da Saúde, que discute a lógica do cuidado na área da Saúde Mental voltada a crianças e adolescentes, trazendo alguns apontamentos acerca da atenção ao sofrimento psíquico desses. Dentre os pontos abordados nesse texto, destaca-se a importância da constituição de uma rede ampliada de atenção para esse público, pautada na intersetorialidade e na corresponsabilidade dos envolvidos.

Outro documento bastante relevante e recentemente divulgado chamado Linhas de cuidado para atenção às pessoas com Transtornos do Espectro do Autismo e suas famílias na rede de atenção psicossocial do Sistema Único de Saúde (Brasil, 2013). Este visa traçar os princípios básicos para o atendimento das pessoas com TEA na rede de serviços do Sistema Único de Saúde e propor alternativas em relação às formas de lidar com esses sujeitos, principalmente no que tange: aos direitos a eles reservados, à construção do diagnóstico por meio de uma equipe interdisciplinar e o trabalho em rede intersetorial no âmbito da saúde, da educação, da assistência e outros setores, tendo em vista a grande complexidade dos casos acompanhados. Assim, a exigência de uma proposta de articulação interdisciplinar no tratamento do autismo implica questões singulares de cada caso.

A psicanálise, nesse sentido, contribui para a concretização do aspecto ético de tratamento que a psicose comporta, apostando na possibilidade de 


\section{SAÚDE MENTAL}

construção de uma solução singular por parte dos sujeitos dessa estrutura. Quinet (2006) diz que o fora-do-discurso próprio à psicose indica uma impossibilidade estrutural de fazer o psicótico entrar completamente no laço social e circular entre os diversos discursos. Assim, o ponto central da posição que assumimos na política institucional é de "introduzir o sujeito como tal" (Lacan, 1966/2003c, p. 220).

Conforme expõe Lacan (1969-70/1992): “A intrusão na política só pode ser feita reconhecendo-se que não há discurso - e não apenas o analítico - que não seja do gozo, pelo menos quando dele se espera o trabalho da verdade" (p. 74). Assim, ao nos determos nas particularidades estruturais do sujeito dito autista, constatamos como coordenada que "para além do estilo e das manobras de cada um, [todos se prestam] à mesma política: o ato do sujeito e o tratamento do gozo" (Baio, 1999, p. 72). Ademais, a experiência clínica aponta que os autistas estão constantemente na tentativa de "lidar com a dispersão do gozo, com as dificuldades pulsionais" (Zenoni, 2000, p. 48). Logo, o trabalho clínico a eles direcionado se constitui a partir da tentativa de dissolver o gozo invasor e produzir condições que permitam aparecer o ato do sujeito.

Seguindo esta direção, conforme aponta Viganò (2006): "Não é o sujeito que 'deve' respeitar as instituições, mas é a instituição que só será respeitada se tiver vontade de dar ao sujeito uma representação, um lugar no vínculo social" (p. 30). Assim, privilegia-se a posição política de fazer com que os responsáveis pelo caso se questionem acerca da condução do mesmo e atuem no mesmo registro que o paciente. Para tanto, é preciso um esforço constante de fazer com que a palavra dos vários envolvidos no caso esteja circulando e em interlocução.

No que se refere à experiência de extensão mencionada, observou-se que na junção do trabalho a partir da psicanálise e do campo da Atenção Psicossocial/campo institucional, o método de Construção de Caso Clínico ${ }^{3}$

${ }^{3}$ A utilização deste método na extensão é fundamentada a partir das etapas propostas por Viganó (1999), responsável pela formulação desse dispositivo. Tais etapas compreendem: 1. Coleta da narrativa (da criança, seus familiares e os envolvidos no caso); 2 . As escansões do tratamento (tais como posicionamento diante da equipe, as demandas, transferência, impasses subjetivos etc.) e, 3. O cotejamento entre o diagnóstico do DSM (Manual de Diagnóstico e Estatística dos Transtornos Mentais) IV ou CID-10 (Classificação Estatística Internacional de Doenças e Problemas Relacionados com a Saúde). 
se mostrou um instrumento privilegiado no sentido de manter o diálogo da psicanálise com os demais setores e saberes, introduzindo a palavra do próprio paciente na construção do PTS.

Pensar as consequências da psicanálise no trabalho institucional implica considerar que a dimensão do sujeito deve orientar o trabalho e as diretrizes básicas. A prática analítica comporta um aspecto político que se refere à tentativa de estabelecimento do laço social e à ética da responsabilidade. Rinaldi (2005) aponta que um dos grandes problemas encontrados no trabalho com a psicose no campo da Atenção Psicossocial refere-se à falta de articulação entre clínica e política, uma vez que constantemente os técnicos em suas práticas não consideram a dimensão do sujeito no que tange à cidadania e abordam o sujeito psicótico a partir de um caráter paternalista, reproduzindo práticas tutelares que deveriam ser excluídas desse contexto, marcando um retrocesso na recuperação da autonomia destes.

Na clínica da psicose, não se trata, portanto, de um ideal do bem, mas, antes de tudo, deixar-se orientar pelo singular do sujeito, possibilitando que a própria instituição se reconstrua para cada caso. Ou, como nos diz Lacan, (1955-56/1988), deve haver uma posição de "submissão completa, ainda que advertida, às posições propriamente subjetivas do doente" (p. 540).

Sustentar o discurso analítico no contexto institucional encontra grandes impasses, pois o trabalho de escuta implica diversos fatores como o campo do Real, a aposta no laço social e a diferença absoluta do sujeito. Entende-se, assim, que o lugar do analista não é marcado por uma delimitação específica, mas se constrói a partir da interação diária com os pacientes e no diálogo com os demais discursos que ocupam o contexto no qual se insere, operando a partir do discurso analítico que pretende produzir um furo no saber unificador e padronizado.

\section{Pressuposto Ético: O ato que dar lugar ao saber do sujeito}

Dizer que um dos pressupostos do projeto Água de Chocalho refere-se à condução do tratamento baseada na ética da psicanálise, implica considerar que ele se estrutura a partir da suposição do saber inconsciente e da escuta dos atravessamentos que a clínica apresenta, implicando, por sua vez, o trabalho subjetivo e a invenção a partir dos recursos escolhidos por cada um.

A dimensão ética da psicanálise não está relacionada a uma ordenação ou um bem a ser atingido (Lacan 1959-60/1997), mas está ligada ao ato da fala 


\section{SAÚDE MENTAL}

restituindo ao sujeito seu próprio desejo. É a partir dessa concepção, tributária da noção do sujeito como uma função/efeito de linguagem, que podemos abordar a questão que os sujeitos autistas nos convocam a responder: Qual a relação que cada um mantém com a linguagem e com o Outro?

A ética da psicanálise implica que, mesmo diante de casos onde há recusa frente ao Outro, deve-se supor uma escolha do sujeito, mesmo que insondável, e um arranjo produzido por ele para suportar a dimensão caprichosa desse Outro, uma vez que, nesses casos, a falta parece não ter sido subjetivada.

Nessa perspectiva, dar destaque ao sujeito e incluí-lo em seu tratamento é considerar suas articulações como fala, suas respostas singulares, sua história e o que ele tem a dizer sobre sua condição. No que concerne à psicose, mesmo que as produções subjetivas possam abolir o sentido, apostar nelas e legitimá-las possibilita a construção de um lugar próprio de existência, afinal, apostar na singularidade também é um ato ético (Oury, 1988/1989, p. 12).

\section{Pressuposto Clínico: ênfase no singular de cada sujeito}

A principal orientação clínica do projeto Água de Chocalho é acolher as manifestações das crianças, deixando-as livres para construir recursos que as ajudem a lidar com o que as aflige. Assim, tentamos inscrever significantes e incluí-las no trabalho para que novas invenções possam advir. Seguimos as indicações de Lacan (1975/2016, p. 73) quando afirma que aconselhava seus supervisionandos a "seguirem o movimento" das crianças ditas autistas, pois chamá-las assim é uma precipitação, é ir rápido demais.

Ademais, tomamos como inspiração a experiência desenvolvida por Luciano Elia (2009), nomeada "Psicanálise com muitos". Tal recurso - estabelecido como uma experiência brasileira nos dispositivos de Saúde Pública e Mental em nosso país — é fundamentado com o objetivo de favorecer um dispositivo para o trabalho com pacientes de estrutura psicótica, de forma que a instituição se adeque às singularidades desses sujeitos.

A "Psicanálise com muitos" propõe consideração "às dificuldades destes sujeitos diante de uma posição analítica de sujeito suposto saber e diante da transferência no um a um do dispositivo clássico psicanalítico" e, portanto, visa promover um espaço "com muitos", que dissolva o Um e lhe dê um status menos avassalador na relação, permitindo ao psicótico apreender que este 
Um não é completo e que também está em relação a outros e que estes outros também estão em trabalho com o paciente atendido (Dias, 2009, p. 101).

Essa orientação aponta para uma destituição subjetiva por parte dos membros da equipe e a suspensão de seu saber em relação aos casos, acompanhando, assim, as exigências impostas pela estrutura subjetiva da criança.

Logo, cada membro da equipe deve estar aberto ao revezamento contínuo entre os técnicos, de forma que não se constituam posições definidas e unificadas, permitindo que a criança possa dirigir-se a alguém que sinta menos invasivo, uma vez que pode escolher com quem interagir e vincular entre os presentes. Esse revezamento pressupõe não apenas os membros da equipe, mas todos que ocupam o espaço, como, por exemplo, as outras crianças. No entanto, é preciso que a criança aceite e legitime alguém para acompanhá-la. Para isso, é preciso deixar com que o saber esteja do lado dela, como forma de assegurar uma presença regulada (Baïo, 1999). Coerentes com a política relativa à educação inclusiva - entendemos que a presença de outras crianças "fura" a estrutura maciça da transferência, presentificada pelo olhar do cuidado exclusivo individualizado. Assim, respeita-se a condição e o ritmo do sujeito na sua relação com as outras pessoas.

Pretende-se possibilitar um espaço no qual o discurso sobre a criança possa ser sustentado. Tal sustentação necessária à clínica da psicose e do autismo representa o que Figueiredo e Machado (2000) apontam como "presença reservada", ou seja, o ato de construir uma condução em que se tenha a disponibilidade suficiente para que o acompanhamento do sujeito psicótico aconteça, mas respeitando o espaço deste, de modo que ele permaneça no ambiente com sua forma específica de relacionar-se.

No Água de Chocalho procura-se manter um saber "não todo" entre os membros da equipe. Essa política da falta-a-ser busca a possibilidade do aparelhamento do excesso de gozo e favorecer novas produções e invenções, além do estabelecimento de laços sociais.

Outra baliza de trabalho é referente ao que se chama de Tratamento do Outro. Essa expressão de Alfredo Zenoni (1991) nomeia o trabalho constante que o sujeito psicótico realiza para regular o Outro, ou seja, o que lhe chega pelo lado de fora, no Real. Tal trabalho pressupõe uma direção clínica que considera o campo do Outro do sujeito psicótico no registro de um excesso ou de uma invasão, e, devido a isso, busca possibilitar que cada um dos envolvidos que acompanha os casos, se coloque como parceiro no "Tratamento do Outro", possibilitando um contato menos excessivo. Assim, 


\section{SAÚDE MENTAL}

percebe-se que "é a natureza da clínica em questão que exige uma resposta 'entre vários', o que exige a formação de uma equipe" (Zenoni, 2006, p. 4).

\section{Invenção e estabilização}

Na década de 1970, os remanejamentos conceituais elaborados por Lacan (1975-76/2007) implicaram nitidamente a clínica da psicose e trouxeram outra perspectiva em relação ao tratamento, uma vez que, naquele momento, a teoria do Nome-do-pai é modificada. Nessa perspectiva, não há apenas um significante que pode funcionar como ordenador possível para a ancoragem do sujeito na sua história, mas outros significantes que podem operar essa função. Assim, a discussão em torno da psicose passa a não se resumir apenas à procura de soluções devido à foraclusão de um significante - o Nome-do-pai - mas perpassa agora em torno das soluções singulares de cada sujeito para localizar/condensar o gozo. É justamente na discussão acerca dessas soluções singulares que se pode destacar o caráter das invenções na clínica da psicose.

Miller (2003, p. 6) discute o conceito de invenção, apontando a distinção desse termo com a noção de criação, uma vez que não é algo construído a partir do nada, mas trata-se de uma invenção "a partir de materiais existentes", que o sujeito poderá extrair de sua história e de sua própria vivência a partir de lalíngua. Alguns autores nomeiam essa construção em que se empenha o sujeito autista de bricolagem ${ }^{4}$ (Miller, 2003; Di Ciaccia, 2003) e relacionam com a amarração produzida no sinthoma ${ }^{5}$ (Baio, 2006). Miller (2003) aponta que o próprio encontro com o analista já se configura como um recurso à invenção. Logo, a invenção implica um trabalho psíquico que se manifesta

${ }^{4}$ Termo proveniente do francês bricolage, que se refere a uma atividade artesanal, construtiva e privada, a partir da qual não é necessária uma especialização ou técnica para efetuá-la. Lévi-Strauss (1976) descreve essa noção, diferenciando a atividade de bricolagem da atividade de um engenheiro, pois nesta última, o que se apresenta é a construção de objetos a partir de uma técnica. Já na bricolagem, a construção é feita a partir do que está disponível na natureza, com restos considerados sem utilidade, que são reciclados em um novo objeto e adquirem um novo uso.

${ }_{5}^{5}$ Termo elaborado por Lacan (1975-1976/2007, p. 44) para referir-se a um quarto elo que enodaria, topologicamente, os registros Real, Simbólico e Imaginário. O sinthoma, portanto, além de ser capaz de realizar uma economia de gozo, seria um suporte para o sujeito. 
— principalmente nos sujeitos que são marcados por uma foraclusão — por meio de uma materialidade das palavras e uma apropriação dos recursos no campo do Real.

Consideramos que nos dispositivos de Saúde Mental - e no Água de Chocalho - testemunhamos as mais diversas soluções singulares, inventadas pelos sujeitos na busca de uma estabilização ou uma mediação na relação com o Outro, conforme a estrutura clínica. Observou-se que não são, por exemplo, os instrumentos musicais e outros objetos que funcionam como elementos de estabilização e construção de laço com o Outro, mas o que deles o sujeito pode usar a seu favor, como um savoir-faire com lalingua.

Na clínica do autismo testemunhamos as produções que acabam sendo tratadas como algo aleatório e fora de sentido, mas, no entanto, podem ser tomadas em um sentido "linguageiro", o que nos faz considerar sempre as palavras nas coisas. Lacan (1955-56/1988) o confirma: “o sujeito psicótico está numa relação direta com a linguagem em seu aspecto formal de significante puro. Tudo que se constrói ali não passa de reações de afeto ao fenômeno primeiro, a relação com o significante" (p. 284). Assim, na clínica da psicose, o trabalho implica sustentar a particularidade estrutural da posição 326 do sujeito, produzindo a possibilidade de um endereçamento. Conforme Soler (2007), a incidência do ato analítico tem papel fundamental no tratamento dos excessos de gozo impostos ao sujeito psicótico.

Testemunhou-se que no acompanhamento das crianças e de suas construções subjetivas, alguns significantes puderam ser destacados, possibilitando uma abertura ao simbólico e uma retomada de fala. Alguns casos atendidos suscitaram questões relacionadas ao papel da invenção para a estabilização no autismo. Propomos, portanto, rastrear alguns caminhos pelos quais a invenção de um recurso singular por parte da criança resultou em uma estabilização e amenização do sofrimento.

\section{Caso Lara: produção de uma enunciação}

Lara, uma menina de oito anos que nos foi encaminhada através de sua escola devido às suas frequentes crises de agressividade. A garota apenas conseguia assumir uma enunciação através da música e, na maioria das vezes, a única condição para que verbalizasse algo era cantando. Fazia isso até mesmo em meio às suas crises de agressividade. Em um dos atendimentos de Lara, a garota canta o refrão “Oh, Anna Júlia!” da música Anna Júlia (Los Hermanos), 


\section{SAÚDE MENTAL}

repetidamente, sem que impedíssemos. Em certo momento, ela troca a letra da música, mas com a mesma melodia, cantando de forma rimada "Oh, me ajuda!". O que percebemos é uma enunciação na qual o sujeito apaga sua presença na melodia, "camuflando" seu lugar no direcionamento da demanda. Pimenta (2012, p. 147), recorrendo a Maleval (2009), refere-se a esse tipo de enunciação dos autistas como "enunciação alusiva". O tocante nesse exemplo foi percebermos que ao mesmo tempo a garota enunciava sua posição de sofrimento numa crise, mas estava aprisionada a uma maneira de dizê-lo, uma holófrase (Peusner, 2016; Lacan, 1964/1993), na qual o intervalo significante que localiza o sujeito se apaga no efeito imaginário da reprodução melódica.

É com a música que Lara constrói/inventa, com lalíngua, uma forma de livrar-se, momentaneamente, da invasão de gozo, tentando reconstruir-se como sujeito. Nesse episódio, a analista responde dizendo "Eu ajudo, Lara", validando a construção da garota e sua forma singular de lidar com aquilo que a invade. Ao que a garota para de cantar e retruca: "Ajuda?".

A importância da música para Lara como forma de enunciação passa a ser um dos principais aspectos discutidos nas reuniões de construção do PTS de Lara. O uso que fazia das letras e melodias passa a ser considerado pelos profissionais da rede intersetorial, de forma a delimitar uma condução clínica que sustentasse suas construções.

\section{Caso Luiza: Da recusa monitorada à regulação simbólica}

Luiza, uma criança autista de oito anos, chegou ao CAPS II com diagnóstico de autismo e constantemente dava sinais do quanto a linguagem pode ser invasiva e devastadora para o sujeito: ora tapando os ouvidos, ora repetindo frases de forma ecolálica, monitorando o que lhe era falado. Quando escolhia falar algo, expressava-se com uma voz diferente, que segundo sua mãe tratava-se da imitação de um desenho animado que sempre assistia. Luiza utilizava as palavras desabitadas de subjetividade, sem intencionalidade de demanda ou expressão pessoal, de forma automática e sem direcionamento. Sua mãe a munia de técnicas educativas para o uso funcional da linguagem, sem, no entanto, considerar a singularidade da enunciação de sua filha.

Além disso, a garota, mesmo sendo acompanhada durante vários anos no Centro de Atenção Psicossocial, era considerada por muitos profissionais como uma criança que não entendia os comandos ou que estava aquém do laço social. Sobre esse aspecto, afirma Lacan (1967/2003a): "Mas o que 
pergunto [...] que questiono, é se, sim ou não, uma criança que tapa os ouvidos — dizem-nos: para quê? para alguma coisa que está sendo falada já não está no pré-verbal, visto que se protege do verbo" (p. 365).

Quanto às atividades em grupo, Luiza nunca acompanhava, sempre circulando pela sala, repetindo frases de forma monocórdia ou escondendo-se embaixo da mesa. Em um dos grupos de crianças, foi proposta uma atividade na qual as crianças deveriam dançar com um balão enquanto a música tocava e, logo depois, tinham de ficar paradas tão logo a música silenciasse. Assim, enquanto a música tocava, ${ }^{6}$ Luiza dançava com o seu balão e logo passa a reger a atividade, de modo que controlava a música dizendo "Estápua!"7 no momento em que todos deveriam ficar parados. Quando todos paravam, Luiza prosseguia dizendo com uma voz monocórdia "Ele não parou? Acho que sim" e logo depois a garota fazia a contagem do tempo de forma melódica dizendo "Um, dois, três!" até o momento em que a música deveria ser retomada.

No jogo instituído por Luiza, ela consegue conectar as palavras e os objetos de forma controlada e constante, deixando uma brecha ao laço social, advindo como sujeito de comandos rígidos. $\mathrm{Na}$ sua tentativa de regular o 328 campo do Outro, a garota manifesta sua relação com o simbólico através da regulação automática do ritmo e suas alternâncias. A garota produz — por meio do controle da atividade - uma regulação/esvaziamento do seu gozo invasor. É importante destacar que decorrido esse fato no qual os outros passaram a fazer o que ela ordenava, Luiza passou a participar ativamente dos grupos de crianças, sempre construindo jogos nos quais se colocava como regente da atividade. Assim, constituiu uma forma de estar no laço social, mesmo que regrando incessantemente a ação do Outro, inventando um modo próprio de enunciação.

\section{Caso Lia: Produção de uma bricolagem a partir de recortes dispersos}

Apresentamos, ainda, outra garota. Lia tinha 11 anos quando chegou em estado grave ao Centro de Atenção Psicossocial. Ela apenas emitia gritos e

${ }^{6}$ Música junina popular, cuja letra era cantada assim: "Cai cai balão, cai cai balão /Aqui na minha mão / Não cai não, não cai não, não cai não/ Cai na rua do sabão".

${ }^{7}$ Momento em que normalmente todos dizem: "Estátua!". 


\section{SAÚDE MENTAL}

sons indiferenciados, sem estabelecer propriamente qualquer interação com as outras pessoas e tampouco dirigia o olhar para os outros. Segundo sua mãe, Lia não se alimentava, não aceitava ser alimentada, não ia à escola e não usava o banheiro por conta própria. Era bastante conhecida pelas pessoas do serviço por sempre chegar aos atendimentos com uma sacola cheia de revistas, além de guardar algumas outras que estivessem na recepção ou em algum outro ambiente da instituição. Se alguém dissesse a ela que não era possível levar as revistas para casa, Lia ficava agitada e agredia as pessoas ao seu redor. A mãe, ao ser questionada pelos profissionais acerca do que Lia gostava de fazer, responde indiferentemente: "Ela não gosta de nada, não faz nada, só passa o dia recortando revistas e eu tenho que limpar tudo". A fala da mãe apontou-nos um indício de um recurso possível a partir do qual poderíamos trabalhar. Com o tempo, passamos a pedir que as pessoas do serviço não mais a impedissem de guardar as revistas, acrescentando que elas poderiam, inclusive, contribuir com novas revistas para sua coleção. Acompanhando seu trabalho de recortes, percebemos o caráter não aleatório das figuras escolhidas, que se caracterizavam por fragmentos referentes à sua história, tais como a descrição do pai feita pela mãe, que segundo ela, havia abandonado a criança. Percebemos também palavras dispersas, relacionadas ao discurso da mãe sobre Lia, como a queixa em relação à escola e a dificuldade em alimentar-se.

Nesse sentido, conforme a recomendação de que o analista deve operar guiando-se pelos termos verbais do sujeito que fala (Lacan, 1955-56/1988), acompanhamos Lia em seu trabalho, que com o tempo passou a entregar e endereçar os seus recortes a algumas pessoas da equipe. Recortes que veiculavam frases entendidas por nós como uma forma de comunicação, ao que, portanto, sempre respondíamos à Lia enxertando palavras. A ação outrora tida como dispersa, era, agora, uma forma de mediação com o Outro. Testemunhamos nesse caso que foi justamente o traumatismo do significante que obrigou o sujeito a uma invenção (Miller, 2003).

Consideramos que o trabalho de invenção no qual o sujeito autista se engaja, constitui-se como uma bricolagem que visa constituir recursos frente ao gozo do Outro, sejam estes linguísticos, musicais, materiais ou a partir de uma apropriação real com lalíngua. Logo, para que esses recursos ganhem um estatuto de artifício de estabilização, é necessário que o analista o legitime e o eleve à condição de mensagem endereçada, tentando incluir um trabalho de articulação significante no que o paciente já construiu. 
Nos casos expostos podemos observar manifestações consideradas por seu valor autêntico de invenção singular que serviram de estabilização/ ancoragem por parte do sujeito e construção de um enlaçamento social.

\section{Considerações finais}

Com os casos diagnosticados como autistas presenciamos uma posição radical, apresentada por meio de uma recusa constante às demandas do Outro. Diante dessas particularidades, o sujeito procura barrar o gozo do Outro que o invade. Este aspecto destaca a importância da invenção e os caminhos que podem favorecer com que os sujeitos possam forjar suas próprias soluções. O espaço de atendimento, portanto, tornou-se um campo de possibilidades, a partir do qual os técnicos puderam acompanhar as crianças no caminho que elas próprias indicavam, suportando o silêncio ou os gestos repetitivos, aparentemente sem sentido.

$\mathrm{Na}$ função de "secretariado", pudemos testemunhar nas construções desses sujeitos uma tentativa de lidar com o que há de mais singular. Podemos supor que o reconhecimento por parte do Outro, localizando um lugar de enunciação, permitiu com que os sujeitos produzissem algo a partir de sua história, proporcionando uma amenização do seu sofrimento e uma maior estabilização.

O manejo do trabalho foi na direção da articulação do sujeito a partir do que lhe é próprio, não na busca de sentido, mas de uma articulação simbólica que pudesse ter efeito de suplência. Os comportamentos, as jaculações e as invenções foram legitimadas como formas de subjetivação, dando, assim, seu lugar no campo do Outro.

Concluímos que o trabalho no projeto Água de Chocalho - sustentado a partir dos pressupostos da ética, da política e da clínica - possibilita às crianças atendidas uma prática de reconhecimento de suas invenções. Nos casos expostos podemos observar manifestações consideradas por seu valor autêntico de invenção singular com possibilidade estabilização, de ancoragem e de construção de um laço social. 


\section{SAÚDE MENTAL}

\section{Referências}

Baïo, V. (1999, set.). O ato a partir de muitos. Revista Curinga, 13, 66-73.

Baio, V. (2006). Nome-do-Pai e autismo. Scilicet dos Nomes-do-Pai. Textos preparatórios para o congresso de Roma, 13 a 17 de jul., AMP.

Bettelheim, B. (1987). A fortaleza vazia. São Paulo, SP: Martins Fontes. (Trabalho original publicado em 1967).

Brasil (2005). Caminhos para uma Política de Saúde Mental Infanto-Juvenil. Ministério da Saúde. Secretaria de Atenção à Saúde. Departamento de Ações Programáticas Estratégicas. Brasília, 86 p.

Brasil. (2013). Linhas de cuidado para atenção às pessoas com Transtornos do Espectro do Autismo e suas famílias na rede de atenção psicossocial do Sistema Único de Saúde. Ministério da saúde. Secretaria de Atenção à Saúde. Departamento de Ações Programáticas Estratégicas.

Costa, F. A. P. (2004). Folk-lore pernambucano. Recife, PE: Editora CEPE. (Trabalho original publicado em 1908).

Dias, M. (2009). Onde está o sujeito? A transferência na psicanálise com muitos. Dissertação de Mestrado, Universidade Estadual do Rio de Janeiro - UERJ, Rio de Janeiro, RJ, Brasil.

Di Ciaccia, A. (2003). Inventar a psicanálise na instituição. In Os usos da psicanálise (pp. 33-38). Rio de Janeiro, RJ: Contra Capa.

Drapier, J. P. (2012). Autismo: estrutura ou superestrutura? A Peste, 4(1), 37-53, jan. a jun. 2012. Recuperado em 24 jan. 2019, de: $<$ https://revistas.pucsp.br/apeste/ article/view/22104/16213>.

Elia, L. (2009). A psicanálise com muitos na clínica institucional pública de saúde mental infanto-juvenil: relatório prociência triênio 2005-2008 - FAPERJ. Rio de Janeiro.

Figueiredo, A. C., \& Machado, O. M. R. (2000). O diagnóstico em psicanálise: do fenômeno à estrutura. Ágora: Estudos em Teoria Psicanalítica, 3(2), 65-86. https://dx.doi.org/10.1590/S1516-14982000000200004.

Freud, S. (1976). O Inconsciente. In Edição Standard Brasileira das Obras Psicológicas Completas de Sigmund Freud (vol. XIV). Rio de Janeiro, RJ: Imago (Trabalho original publicado em 1915).

Freud, S. (1992a). Psicología de las masas y análisis del yo. In Obras Completas Sigmund Freud (vol. XVIII, pp. 63-136). Buenos Aires, Argentina: Amorrortu. (Trabalho original publicado em 1921).

Freud, S. (1992b). Introducción a J. Varendonck, The Psychology of Day-Dreams. In Obras Completas Sigmund Freud (vol. XVIII, pp. 268-269). Buenos Aires, 
Argentina: Amorrortu. (Trabalho original publicado em 1921).

Freud, S. (1998). Pontuações psicanalíticas sobre um caso de paranoia. Edição Standard Brasileira das Obras Psicológicas Completas de Sigmund Freud (vol. XII). Rio de Janeiro, RJ: Imago (Trabalho original publicado em 1911).

Furtado, L. A. R. (2012). "Cede-se com as palavras para logo ceder com as coisas": observações freudianas sobre alguns mal-entendidos em torno do autismo. $A$ Peste, 4(1), 65-74, jan.-jun./2012. Recuperado em 24 jan. 2019, de: <https:// revistas.pucsp.br/apeste/article/view/22109/16218>.

Grandin, T. M. (2006). Uma menina estranha. São Paulo, SP: Companhia das Letras, 2006.

Klein, M. (1996). A importância da formação de símbolos no desenvolvimento do ego. In Amor, culpa e reparação e outros trabalhos (1921-1945) (A. Cardoso, Trad., pp. 249-264). Rio de Janeiro, RJ: Imago. (Trabalho original publicado em 1930).

Lacan, J. (1979). O seminário. Livro 1. Os escritos técnicos de Freud. Rio de Janeiro, RJ: Zahar. (Trabalho original publicado em 1953-54).

Lacan, J. (1985). O seminário. Livro 20. Mais, ainda. Rio de Janeiro, RJ: Jorge Zahar. (Trabalho original publicado em 1972-73).

Lacan, J. (1988). O seminário.Livro 3. As psicoses. (2a ed.). Rio de Janeiro, RJ: Jorge Zahar. (Trabalho original publicado em 1955-56).

Lacan, J. (1991). Conferencia en Genebra sobre el síntoma. In Intervenciones y Textos 2 (2a ed., pp. 115-144). Buenos Aires, Argentina: Manantial. (Conferência proferida em 4 de outubro de 1975).

Lacan, J. (1992). O seminário. Livro 17. O avesso da psicanálise. Rio de Janeiro, RJ: Jorge Zahar. (Trabalho original publicado em 1969-70).

Lacan, J. (1993). O seminário, Livro 11. Os quatro conceitos fundamentais da psicanálise ( $2^{\mathrm{a}}$ ed.). Rio de Janeiro, RJ: Zahar. (Trabalho original publicado em 1964).

Lacan, J. (1996). Apresentação das memórias de um doente dos nervos. In Outros escritos. Rio de Janeiro, RJ: Jorge Zahar (Trabalho original publicado em 1966).

Lacan, J. (1997). O seminário. Livro 7. A ética da psicanálise. Rio de Janeiro, RJ: Jorge Zahar. (Trabalho original publicado em 1959-60).

Lacan, J. (1998a). Formulações sobre a causalidade psíquica. In Escritos. Rio de Janeiro, RJ: Jorge Zahar. (Trabalho original publicado em 1946).

Lacan, J. (1998b). Função e campo da fala e da linguagem em psicanálise. In Escritos. Rio de Janeiro, RJ: Campo Freudiano do Brasil/Jorge Zahar. (Trabalho original publicado em 1953).

Lacan, J. (1998c). De uma questão preliminar a todo tratamento possível da psicose. In Escritos (pp. 573-590). Rio de Janeiro, RJ: Jorge Zahar (Trabalho original publicado em 1958). 


\section{SAÚDE MENTAL}

Lacan, J. (2002). O desejo e sua interpretação: seminário 1958-1959. Porto Alegre,

RS: APPOA. (Trabalho original publicado em 1958-59).

Lacan, J. (2003a). Alocução sobre as psicoses da criança. In Outros escritos (pp. 359-368). Rio de Janeiro, RJ: Jorge Zahar. (Trabalho original publicado em 1967).

Lacan, J. (2003b). Nota sobre a criança. In Outros escritos. Rio de Janeiro, RJ: Jorge Zahar. (Trabalho original publicado em 1969).

Lacan, J. (2003c). Apresentação das Memórias de um doente dos nervos. In Outros Escritos (pp. 219-223). Rio de Janeiro, RJ: Zahar. (Trabalho original publicado em 1966).

Lacan, J. (2007). O seminário. Livro 23. O sinthoma. Rio de Janeiro, RJ: Jorge Zahar. (Trabalho original publicado em 1975-76).

Lacan, J. (2016). Lacan in North America. Porto Alegre: Editora Fi. (Trabalho original publicado em 1975). Recuperado em 25 mar 2109, de: <https://docs. wixstatic.com/ugd/48d206_445d32c81b984cabb0e1f0915545b928.pdf>.

Laurent, É. (2013). La batalla del autismo: de la clínica a la política. Buenos Aires, Argentina: Grama Ediciones.

Lefort, R. \& Lefort, R. (1980). Naissance de l'Autre. Deux psychanalyses: Nadia, 13 mois, Marie-Françoise, 30 mois. Paris, FR: Seuil.

Lefort, R. \& Lefort, R. (1998). O autismo, especificidade. In Fundação do Campo Freudiano (Org.). O sintoma charlatão. Rio de Janeiro, RJ: Jorge Zahar.

Lefort, R. \& Lefort, R. (2003). La distinction de l'autisme. Paris, FR: Seuil.

Lévi-Strauss, C. (1976). O pensamento selvagem. São Paulo, SP: Ed. Nacional.

Maleval, J. C. (2009). L'autiste e sa voix. Paris, FR: Éditions du Seuil.

Maleval, J. C. (2018). Da estrutura autista. Revista aSEPHallus de Orientação Lacaniana, 13(26), 4-38, mai.-out./2018. Recuperado em 24 jan. 2019, de: <http:// www.isepol.com/asephallus/numero_26/pdf/2_conferencia_jean_claude_maleval_ portugues.pdf $>$.

Miller, J. (2003). A invenção psicótica. Opção Lacaniana, 36.

Oury, J. (1988). A transferência. Transcrição de seminário apresentado na Clínica de La Borde, Cour-Cheverny, 1988-89.

Peusner, P. (2016). Fugir para adiante: o desejo do analista que não retrocede ante as crianças. São Paulo, SP: Agente publicações.

Pimenta, P. (2012). O objeto autístico e sua função no tratamento psicanalítico do autismo. Tese de doutorado, Faculdade de Filosofia e Ciências Humanas, Universidade Federal de Minas Gerais, Belo Horizonte, MG, Brasil.

Quinet, A. (2006). Psicose e laço social. Esquizofrenia, paranoia, melancolia. Rio 
de Janeiro, RJ: Jorge Zahar.

Rinaldi, D. (2005). Clínica e política: a direção do tratamento psicanalítico da saúde mental. In: Altoé, S., \& Lima, M. M. (Orgs.), Psicanálise, clínica e instituições. Rio de Janeiro, RJ: Rios Ambiciosos.

Soler, C. (1998). Joyce: retrato do artista com jovem depreciador. In A psicanálise na civilização (pp. 107-115). Rio de Janeiro, RJ: Contra Capa.

Soler, C. (2007). O inconsciente a céu aberto na psicose. Rio de Janeiro, RJ: Jorge Zahar.

Viganò, C. (1999). A construção do caso clínico em Saúde Mental. Curinga, 13(1), 39-48.

Viganò, C. (2006, jun.). A palavra na instituição. Mental, IV(6), 27-32.

Winnicott, D. (1972). La schizophrénie infantile en termes d'échec d'adaptation. In Mannoni, M. (Org.), Enfance Aliéné. Paris, PR: Union Général d'Éditions. (Trabalho original publicado em 1967).

Zenoni, A. (1991). Traitement de l'Autre. Preliminaire, 03.

Zenoni, A. (2000). Psicanálise e instituição: a segunda clínica de Lacan. Belo Horizonte, MG: Abrecampos.

Zenoni A. (2006, maio). Orientación Analítica en la institución psiquiátrica. Revista Electrónica de la Nueva Escuela Lacaniana - NEL, 1, 1-8. Recuperado em 24 jan. 2019 de: <https://www.yukei.net/wp-content/uploads/2007/01/a_zenoniorientacion-analitica-en-la-institucion-psiquiatrica.pdf $>$.

\section{Resumos}

(Invention and stabilization: an experience with autistic children in Mental Health units)

This article discusses the value of invention work as a form of stabilization in the clinic of autism. It is based on a university extension project aimed at children with severe psychic suffering in which psychoanalysis is used to guide work and treatment. Watching the movement of those children allowed us to single out subjects who, through their particular manifestations, sought to produce something that would stabilize their psychic disorganization. Therefore, we understand that the subjective work involved in the act of invention - as an act through which a subject performs a unique construction of elements of his history based on existing materials - may result in stabilization and mediation with the field of the Other by of the subject, which was observed in this clinical experience..

Keywords: Autism, psychoanalysis, invention, stabilization 


\section{SAÚDE MENTAL}

(Invention et stabilisation: une expérience avec des enfants autistiques dans des dispositifs de Santé Mentale)

Cet article discute de la valeur du travail d'invention en tant que forme de stabilisation dans la clinique pour autistes, basé sur un projet d'extension universitaire destiné aux enfants souffrant de troubles psychiques sévères, dont la psychanalyse guide le travail et le traitement. Au cours de cette expérience, nous avons détecté - en suivant les mouvements de ces enfants - de sujets qui, par leurs manifestations particulières, cherchaient à produire quelque chose qui stabiliserait leur désorganisation psychique. Ainsi, il est entendu que le travail subjectif impliqué dans l'acte de l'invention - comme acte de construction unique d'éléments de l'histoire du sujet à partir de matériaux existants - peut aboutir à une stabilisation et à une médiation du champ de l'Autre de la part du sujet, ce qui a été observé dans cette expérience clinique..

Mots clés: Autisme, psychanalyse, invention, stabilisation

(Invención y estabilización: una experiencia con niños autistas en dispositivos de Salud Mental)

El artículo discute el valor del trabajo de invención como forma de estabilización en la clínica del autismo, a partir de un proyecto de extensión universitaria dirigido a niños con graves trastornos psíquicos, que tiene al psicoanálisis como orientador del trabajo y del tratamiento. Durante esta experiencia, podemos presenciar - desde el seguimiento del movimiento de estos niños - sujetos que, a través de sus manifestaciones particulares, buscaron producir algo que estabilizara su desorganización psíquica. Por lo tanto, se entiende que el trabajo subjetivo involucrado en el acto de la invención - como el acto en el que un sujeto realiza una construcción única de elementos de su historia a partir de elementos existentes - puede resultar en una estabilización y mediación con el campo del Otro por parte del tema, algo que puede ser observado en esta experiencia clínica.

Palabras clave: Autismo, psicoanálisis, invención, estabilización

Citação/Citation: Viana, B. A., Furtado, L.A.R., \& Vieira, C. A.L. (2020, jun.). Invenção e estabilização: uma experiência com crianças autistas em dispositivos de Saúde Mental. Revista Latinoamericana de Psicopatologia Fundamental, 23(2), 313-336. http://dx.doi. org/10.1590/1415-4714.2020v23n2p313.9.

Editora/Editor: Profa. Dra. Ilka Franco Ferrari

Submetido/Submitted: 15.7.2019/ 7.15.2019 Revisado/Revised: 4.2.2020 / 2.4.2020

Aceito/Accepted: 2.3.2020 / 3.2.2020

Rev. Latinoam. Psicopat. Fund., São Paulo, 23(2), 313-336, jun. 2020 
Copyright: (C) 2009 Associação Universitária de Pesquisa em Psicopatologia Fundamental/ University Association for Research in Fundamental Psychopathology. Este é um artigo de livre acesso, que permite uso irrestrito, distribuição e reprodução em qualquer meio, desde que o autor e a fonte sejam citados / This is an open-access article, which permits unrestricted use, distribution, and reproduction in any medium, provided the original authors and sources are credited.

Financiamento/Funding: Este trabalho recebeu apoio da Fundação Cearense de Apoio ao Desenvolvimento Científico e Tecnológico - FUNCAP / This work was funded by the Fundação Cearense de Apoio ao Desenvolvimento Científico e Tecnológico FUNCAP

Conflito de interesses/Conflict of interest: Os autores declaram que não há conflito de interesses. / The authors declare that there is no conflict of interest.

\section{Beatriz Alves Viana}

Mestre em Teoria Psicanalítica pela Universidade Federal do Rio de Janeiro - UFRJ (Rio de Janeiro, RJ, Br).

Av. Pasteur, 250 - Urca

22290-240 Rio de Janeiro, RJ, Br

beatrizalvesv@gmail.com

336 https://orcid.org.0000-0002-8758-8913

\section{Luis Achilles Rodrigues Furtado}

Prof. Associado do Programa de Pós-Graduação Profissional em Psicologia e Políticas Públicas da Universidade Federal do Ceará, Campus de Sobral (Sobral, CE, Br). Bolsista de Produtividade da Fundação Cearense de Apoio ao Desenvolvimento Científico e Tecnológico - FUNCAP.

Rua Coronel Estanislau Frota, 563 - Centro

62010-560 Sobral, CE, Br

luis_achilles@ufc.brluis.achilles@gmail.com

https://orcid.org.0000-0003-1606-2073

\section{Camilla Araújo Lopes Vieira}

Profa. Adjunta do Programa de Pós-Graduação Profissional em Psicologia e Políticas

Públicas da Universidade Federal do Ceará, Campus de Sobral (Sobral, CE, Br).

Rua Coronel Estanislau Frota, 563 - Centro

62010-560 Sobral, CE, Br

camillapsicol@ufc.br

https://orcid.org/0000-0003-1706-3772

This is an open-access article, which permits unrestricted use, distribution, and reproduction in any medium for non-commercial purposes provided the original authors and sources are credited. 